\title{
PI3Kinase signaling in glioblastoma
}

\author{
M. M. Lino • A. Merlo
}

Received: 9 March 2010/ Accepted: 21 October 2010/Published online: 10 November 2010

(C) The Author(s) 2010. This article is published with open access at Springerlink.com

\begin{abstract}
Glioblastoma (GBM) is the most common primary tumor of the CNS in the adult. It is characterized by exponential growth and diffuse invasiveness. Among many different genetic alterations in GBM, e.g., mutations of PTEN, EGFR, p16/p19 and p53 and their impact on aberrant signaling have been thoroughly characterized. A major barrier to develop a common therapeutic strategy is founded on the fact that each tumor has its individual genetic fingerprint. Nonetheless, the PI3K pathway may represent a common therapeutic target to most GBM due to its central position in the signaling cascade affecting proliferation, apoptosis and migration. The read-out of blocking PI3K alone or in combination with other cancer pathways should mainly focus, besides the cytostatic effect, on cell death induction since sublethal damage may induce selection of more malignant clones. Targeting more than one pathway instead of a single agent approach may be more promising to kill GBM cells.
\end{abstract}

Keywords GBM $\cdot$ PI3K $\cdot$ Apoptosis $\cdot$ Proliferation

$\begin{array}{ll}\text { Abbreviations } \\ \text { CNS } & \text { Central nervous system } \\ \text { GBM } & \text { Glioblastoma } \\ \text { PTEN } & \text { Phosphatase and tensin homologue } \\ \text { EGFR } & \text { Epidermal growth factor receptor } \\ \text { Moabs } & \text { Monoclonal antibodies } \\ \text { PKI } & \text { Protein kinase inhibitors }\end{array}$

M. M. Lino $(\square) \cdot$ A. Merlo

Laboratory of Molecular Neuro-Oncology and Departments of Neurosurgery, University Hospitals, Hebelstrasse 20, 4031 Basel, Switzerland

e-mail: maddalena.lino@unibas.ch

\begin{tabular}{|c|c|}
\hline VEGF & Vascular endothelial growth factor \\
\hline ATM & Ataxia telangectasia mutated \\
\hline ATR & Ataxia teleangectasia rad3 related \\
\hline DNA- & $\begin{array}{l}\text { DNA-dependent serine/threonine protein } \\
\text { kinase }\end{array}$ \\
\hline CTMB & Carboxyl-terminal modulator protein \\
\hline SNPs & Single nucleotide polymorphism \\
\hline RTEL1 & Regulator of telomere elongation helicase \\
\hline CDKN2B & Cyclin-dependent kinase inhibitor 2B \\
\hline MGMT & thyl-guanine-DNA-methyl-trans \\
\hline IMR & Mismatch repair \\
\hline
\end{tabular}

\section{Introduction}

Gliomas, originating from the predominant glial tissue in the CNS, are the most common primary tumors of the central nervous system (CNS) in adults [1]. The prevalent form is astrocytoma WHO grade IV or glioblastoma (GBM). In affected patients, median survival is less than 1 year [2, 3]. Gliomas consist of 3 different tissue types: astrocytomas (about 70\%), oligodendrogliomas (10-30\%) and ependymomas (less that 10\%). Malignant astrocytomas include tumors of WHO grade II (low-grade malignancy), III (anaplastic stage) and IV (highly malignant form, also named GBM) [4]. GBM accounts for approximately 50\% of all glial tumor types. They are characterized by rapid growth and diffuse invasiveness into the adjacent brain parenchyma. Only the nodular component of the disease can be controlled surgically. The infiltrative component of the tumor, however, is left to non-specific and cytotoxic chemo- and radiotherapy that may control tumor progression for a limited time window. 


\section{Molecular genetics of GBM}

The stochastic and complex process of brain tumorigenesis involves activation of oncogenes and inactivation of tumor suppressor genes [5-7]. A large number of genetic alterations have been detected and catalogued in different brain tumors. Familial cancer syndromes, although rare, provided a first clue to understanding the role of specific genes, their associated pathways and to testing them in animal models.

The most common genetic alterations detected in gliomas are loss of heterozygosity at 10q, PTEN mutation [8], and EGFR amplification/overexpression, along with EGFRvIII expression [9, 10], p16/p14 co-deletion [11-13], p53 mutation [14, 15], MDM2 amplification [16], loss of 1p/19q [17], and telomerase re-activation [18]. Besides these classic mutations, a recent comprehensive analysis was able to confirm the known mutations and discovered still unknown genes mutated in GBM, although at low frequency. Interestingly, mutations in the active site of isocitrate dehydrogenase 1 (IDH1) were detected in 12\% of GBM patients, mostly young patients with secondary GBMs [19].

A specific molecular signature been detected so far for oligodendrogliomas $[17,20]$.

A recent paper from the TCGA (The Cancer Genome Atlas Network) based on gene expression-based molecular classification subdivides GBM into Classical, Mesenchymal and Proneural subtype. Each group shows a different aberration and gene expression, which may predict therapy efficacy. The Proneural subtype was associated with younger age, PDGFRA abnormalities, IDH1 and TP53 mutation and resistance to temozolomide and radiation therapy. The Classical GBM with EGFR abnormalities showed the best reaction to therapy, while the mesenchymal subtype, characterized by high expression of CHI3L1 and MET and NF1 mutation/deletion, reported only a partial response to treatment [21].

Recently, it was shown that high-grade glioma risk is associated with inherited variation in a region of $9 \mathrm{p} 21$ containing CDKN2B and a region of 20q13.3 tagged by two intronic SNPs in RTEL1 [22].

MGMT, a DNA repair enzyme, is associated with glioblastoma sensitivity to alkylating agents. Two different groups reported that patients with glioblastoma containing a methylated MGMT promoter benefited from temozolomide, in comparison with patients that did not have a methylated MGMT promoter [23-25]. Methylation of MGMT promoter has been proved to be an independent and stronger prognostic factor, better than age, stage and tumor grade, and predicting responsiveness of glioma to alkylating agents. The TCGA group found that the mutational spectra in the MMR genes paralleled MGMT methylation status and treatment consequences. MMR deficiency and MGMT methylation together may therefore influence the overall frequency and pattern of somatic point mutations in glioblastoma tumors [26].

Even though GBM share many of these alterations, each individual tumor has its own unique pattern of genetic changes that represents a considerable barrier to the development of therapeutic intervention [27]. The putative Achilles heel of GBM may not be a single major genetic alteration, but rather a secondary acquired imbalance in the aberrant signaling network that impinges on essential regulatory pathways.

In this review, we will describe the PI3Kinase network and its role in GBM.

\section{EGFR and GBM}

EGFR is the first member of the ErbB (Her) family of RTKs. The two main EGFR ligands are EGF and TGF- $\alpha$ (transforming growth factor- $\alpha$ ), among other ligands like beta-cellulin, epiregulin, heparin binding EGF (HB-EGF), and amphiregulin. Ligand binding to EGFR induces receptor phosphorylation, which in turn activates a complex downstream signaling network [28]. Downstream signaling through PI3K-PKB [20], PI3K-Rac-Rho, Ras-Raf-Mek-Erk and Jak-STAT influence proliferation [29], migration [30], invasion, resistance to apoptosis [31, 32], and tumor neovascularization [33, 34] (Fig. 1). Overexpression of EGFR has been found in many different tumor types including GBM, and has been consistently found to be correlated with a poor outcome [12, 35]. Genetic alterations like overexpression, small deletions or mutations can lead to oncogenic upregulation of the receptor [36]. In GBM, activation of EGFR is present in 40-60\% of tumors [37]. The most frequent activating mutation is the EGF mutant receptor vIII (EGFRvIII) [36]. Amplification of EGFR gene in GBM leads to downstream activation of $\mathrm{PI} 3 \mathrm{~K} / \mathrm{PKB} / \mathrm{mTOR} / \mathrm{rpS} 6$. Interestingly, it has been shown that inhibition of EGFR signaling correlates with decrease p-mTOR and p-rpS6 in cells wild-type for PTEN. In contrast, inhibition of EGFR signaling fails to affect p-mTOR or p-rpS6 in cells mutant for PTEN. Recently, a PKB independent pathway linking EGFR to mTOR through PKC (protein kinase C) was described indicating an additional drug target [38].

The role of PI3Kinase in the glioma signaling network

Members of the phosphatidylinositol 3-kinase (PI3K) family are lipid kinases involved in diverse signaling pathways that regulate proliferation, differentiation, migration, trafficking, and glucose homeostasis [39-42]. They contain a p110 catalytic subunit that heterodimerizes with five distinct regulatory subunits ( $\mathrm{p} 85 \alpha, \mathrm{p} 55 \alpha, \mathrm{p} 50 \alpha, \mathrm{p} 85 \beta$, and $\mathrm{p} 55 \gamma)$. The p110 catalytic subunit includes an $\mathrm{N}$-terminal p85 binding 
Fig. 1 The PI3K pathway activates different processes that regulate proliferation, apoptosis and migration. Schematic representation of the signaling pathway activated by receptor tyrosine kinase (RTK) and the PI3K downstream activation. Designed by www.lebensart003.com

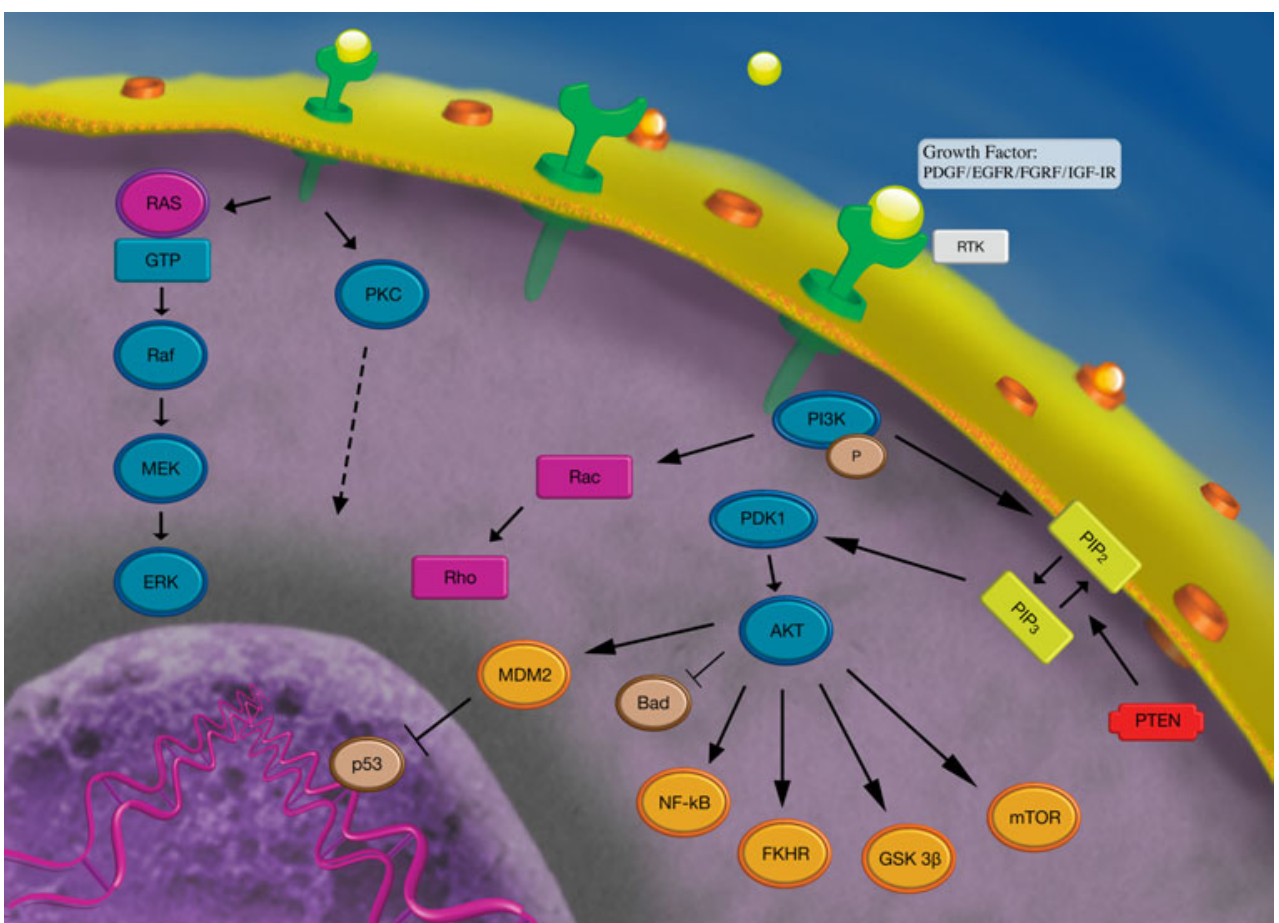

domain, a Ras binding domain, a C2 domain, a phosphatidylinositol kinase homology (PIK) domain, and a C-terminal catalytic domain. The PIK and catalytic domains of p110 are homologous to other protein kinase domains including mTOR, ATM (ataxia telangectasia mutated), ATR (ataxia teleangectasia rad3 related) and DNA-PK (DNA-dependent serine/threonine protein kinase). Mutations within the p110 subunit of PI3K, that are mainly gain of function mutations, have been identified mostly in exon 9 (helical domain) and in exon 20 (kinase domain) [43, 44]. In mammals, 8 distinct PI3K have so far been described. They are divided into classes I-III according to their substrate specificity, regulation and structure. Class I PI3Ks contain two subgroups, IA $(\mathrm{p} 110 \alpha, \mathrm{p} 110 \beta$ and $\mathrm{p} 110 \delta)$ and IB (p110 $\gamma)$, which are activated by growth factor receptor tyrosine kinase (RTKs) and by G-protein-coupled receptors (GPCRs), respectively [42]. Class II PI3Ks consist of a single p110-like catalytic subunit that regulates membrane trafficking and receptor internalization $[41,45]$. Class III PI3Ks has been found to regulate mTOR activity in response to availability of amino acids for the control cell growth [46-48].

PI3K are activated by a wide range of upstream signals and phosphorylate the lipid phosphatidylinositol-4,5,bisphosphate, generating phosphatidylinositol-3,4,5-trisphosphate (PIP3) [41, 42]. The protein serine/threonine kinase PKB (also known as AKT) is the principal PIP3 target. PKB is recruited to the membrane upon binding of PIP3 with subsequent phosphorylation by the mTOR-rictor kinase complex and by PDK1 (3-phosphoinositide-dependent kinase). Activation of PKB, in turn, phosphorylates many target proteins which regulate cell metabolism, cell cycle and cell survival [49, 50], protein synthesis [47], cell polarity, cell motility [51], and vesicle sorting [52] (Fig. 1).

Therefore, the signaling components $\mathrm{PI} 3 \mathrm{~K} / \mathrm{PKB} / \mathrm{mTOR}$ are central regulators of cell proliferation, growth, differentiation, and survival. Moreover, PI3K regulates migration and invasion, mainly by the Rho family members Cdc42, Rac and Rho [53, 54]. These small GTPases dynamically remodel the actin cytoskeleton and give rise to filopodia, lamellipodia and stress fibers $[55,56]$.

$\mathrm{PI} 3 \mathrm{~K}$ dysregulation is observed in a variety of tumors [44, 57-60] including GBM [44, 59], but also in other nonneoplastic human disorders [61]. For example, attenuated PI3K signaling downstream of the insulin receptor significantly contributes to the type- 2 diabetes phenotype [62]. In human cancers, p110 of PI3K is frequently amplified [44]. This observation has been confirmed by another study that described PI3K p110 mutations in 15\% of glioma samples, and $21 \%$ in pediatric and $17 \%$ in adult brain tumor samples [63]. In addition, elements of the PI3K signaling pathway are also frequently mutated, such as PTEN $[64,65]$ and the carboxyl-terminal modulator protein (CTMB) [66, 67]. Transgenic and knockout mouse models have confirmed the role of the PI3K-PBK pathway in tumorigenesis [68]. The TCGA group reported novel in frame deletions in the adaptor domain of PIK3CA. Interestingly in PI3KCA wildtype patients were found mutation in PIK3R1. These mutations clustered always around amino acid residues that disrupt $\mathrm{C} 2$-iSH2 interaction reducing the inhibitory effect of $\mathrm{p} 85 \alpha$ on $\mathrm{p} 110 \alpha$ [26]. 
PTEN (Phosphatase and tensin homologue) tumor suppressor gene encodes a phosphatase that catalyzes the dephosphorylation of phosphatidylinositol 3,4,5 triphosphate (PIP3), negatively regulating the activity of PI3K [8]. The PI3K/PTEN/PKB-pathway is of critical importance for angiogenesis, cell proliferation and survival [31, 50]. Homozygous Pten-knockout mice are embryonically lethal while heterozygous animals are viable but develop various tumors [69]. Loss of function mutations of PTEN are frequent in GBM and activate $\mathrm{PKB}$ in a similar way as mutations in PIK3CA [70]. Epigenetic gene silencing by promoter methylation also inactivates PTEN [71]. In animal models, haploinsufficiency was sufficient to promote tumorigenesis for certain tumor types, and progressive reduction of PTEN resulted in increasingly aggressive tumors [72, 73]. Transfection of PTEN resulted in reduced proliferation and induction of cell cycle arrest at G0/G1, accompanied by inactivation of PKB phosphorylation at Ser-473 [74]. In addition, exogenous PTEN expression induces astrocytic differentiation in the presence of the ECM [74] while neural stem cells self-renewal is negatively regulated by modulating GO-G1 cell cycle entry $[75,76]$. PTEN expression sensitizes GBM cells to radiation, but not to chemotherapeutic drugs [77]. Epigenetic and genetic inactivation of PTEN is associated with shorter survival in GBM patients [8, 12, 78, 79].

\section{PI3Kinase mouse model}

P85 $\beta$ knockout mice develop hypoinsulinemia and hypoglycemia [80, 81]. Loss of all isoforms of PIK3RI (including $\mathrm{p} 50 \alpha$ and $\mathrm{p} 55 \alpha$ ) resulted in perinatal lethality and caused a decrease in the expression and activity of class IA PI3K catalytic subunits. Heterozygous disruption of PIK3Rl improved insulin signaling and glucose homeostasis [82].

Mice carrying homozygous deletions for either $\mathrm{p} 110 \alpha$ or p110 $\beta$ were found to be embryonic lethal [83, 84]. Inhibitors of $\mathrm{p} 110 \alpha$ blocked insulin-stimulated phosphorylation of PKB, while inhibitors of p1 $10 \beta$ had no effect on insulinstimulated phosphorylation. These results suggested that p110 $\alpha$ has a key role in the PI3K-dependent insulin signaling [62]. Direct tumorigenic effect was proved in conditional and prostate-specific PTEN mutation: ablation of p110 blocked PTEN ${ }^{-1-}$-induced tumor formation [85].

\section{Disease targets and ligands}

Glioblastomas may develop de novo (primary GBMs) or through progression from low grade to high-grade astrocytomas (secondary GBMs) [27]. Radiotherapy has been shown to prolong the median survival of GBM patients
[86] and is the standard adjuvant therapy for high-grade GBM, nowadays often combined with the radiosensitizer temozolomide [87]. However, GBM can relapse close to the targeted resection margins or within $2 \mathrm{~cm}$ of the resection cavity. Other therapies such as seed-based brachytherapy [88] or radiosurgery have limited additional therapeutic value. Novel loco-regional treatments using peptide-toxin- or radiolabeled peptide-conjugates are being evaluated [89].

To substantially improve prognosis, more specific therapies are being developed against a number of new critical molecular targets: growth factor receptor inhibitors (gefitinib and erlotinib) [90-92], matrix metalloproteinase inhibitors (marimastat, metastat and prinimastat) [93] and blockers of angiogenesis [94-98]. We will now focus on the role of PI3K in GBM, discuss the effects of PI3K inhibitors on glioma cell survival and proliferation, and perspectives of upstream and downstream interference.

Targeting PI3K and downstream pathway in GBM

Different RTK inhibitors have been developed and studied in different cancer types including GBM, targeting EGFR, PI3K, mTOR and PKB.

\section{Targeting EGFR}

Two different types of EGFR inhibitors have been developed: monoclonal antibodies (MoAbs) and small molecule inhibitors of EGFR tyrosine kinase activity, competing for the ATP binding site. The mechanism of receptor inhibition differs between the two types of drugs. MoAbs interfere with EGFR activation by blocking the extracellular ligandbinding domain. Protein kinase inhibitors (PKI) block the intracellular tyrosine kinase-mediated signaling pathways. Many different MoAbs have been developed with different affinity, specificity and negative regulatory effect. Cetuximab (IMC-225, Erbitux ${ }^{\text {TM}}$; ImClone systems, Princeton, NJ, USA), a MoAb which binds EGFR with higher affinity than the natural ligands, has fairly recently been FDAapproved for treatment of patients with EGFR-positive metastatic colorectal cancer, and since December 2005 by Swissmedic for the treatment of patients with squamous cell carcinoma of the head and neck in combination with radiotherapy. Regarding GBM, the hR3 (TheraCIM; CIMYM Biosciences, ON, Canada), a human high affinity $\mathrm{MoAb}$ to EGFR that is now in phase I/II clinical trial (NCT00369252), has shown a partial response in a GBM study. The use of mAb 806 (Ludwig Institute, Victoria, Australia) that targets mutant EGFRvIII on glioma cell lines and mouse xenografts overexpressing EGFRvIII led to a dose-dependent growth inhibition [99]. Mab-806 is now in preclinical trial in an orthotopic murine glioma 
model, using EGFRvIII-positive U87MG cells [100]. Moreover, a combinatorial study, which uses mAb 806 and $\mathrm{mAb} 528$, showed additive antitumor activity in human tumor xenografts [99]. The use of Cetuximab in tumor cell lines and a xenograft model induces apoptosis and inhibits angiogenesis [101, 102]. The small molecule inhibitors of EGFR are less specific than the MoAb and therefore the clinical effect was found to be less predictable. Nevertheless, these drugs have a low molecular weight, allowing better tumor penetration and can be administered orally. Gefitinib (ZD1839; AstraZeneca, Wilmington, DE, USA) and Erlotinib (OSI-774, CP-358, 774, Tarceva; OSI Pharmaceuticals, in collaboration with Genentech and Roche Pharmaceuticals) have been FDA-approved for different cancer types and new clinical trials in GBM patients are ongoing. Gefitinib showed only a limited activity in GBM patients [103] and colorectal cancer [104]. It did not improve survival as mono-therapy in patients with nonsmall cell lung cancer stage III nor when following chemotherapy and radiation therapy [105]. AEE-788 (LymphoSign), a potent EGFR and VEGF2 inhibitor, is currently in Phase I clinical trial (NCT00116376) for GBM. Erlotinib appears to be more effective against malignant glioma than gefinitib when comparing the radiographic response rate, but none of them have a clear impact on survival.

The limited effect of these PKI against EGFR raised the question whether drug efficiency could not be improved by a combinatorial strategy. In a pre-clinical GBM cell line model blocking EGFR activity with the protein kinase inhibitory drug AEE788, we found a 10-20\% reduction of cell proliferation but only a limited pro-apoptotic effect in the minority of GBM cell lines [106]. Gleevec (PKI of the PDGF receptor developed by Novartis) that inhibits Bcr$\mathrm{Abl}$ and also has an activity against PDGFR and c-kit combined with AEE788 (Novartis) and RAD001 (an ana$\log$ of rapamycin that inhibits mTOR developed by Novartis) was only marginally effective. However, the combination of AEE788 and patupilone (a cell cycle inhibitor blocking polymerization of microtubuli, developed by Novartis) synergistically induced apoptosis in 50\% of GBM cell lines [106]. A synergistic effect was also found when combining erlotinib with the PI-103 that led to an increased proliferation block when compared with monotherapy or a combination of erlotinib and rapamycin. Such combinations may be effective against EGFR-driven PTEN mutant tumors [107]. EGFRvIII expression in GBM promotes DNA-PKcs (DNA dependent protein kinas catalytic subunit) and DBS (DNA double-strand breaks) repair most probably through the augmented PI3K/Akt1 signaling. This mechanism suggests that blocking the DBS and DNA-PKcs pathway together with an EGFR inhibition could lead to better results [108]. Using the EGFR inhibitor gefinitib together with an HMG-CoA reductase induces another interesting synergism, irrespective of EGFRvIII and PTEN status [109].

\section{PI3K inhibitors}

Several compounds inhibiting PI3K have been developed, e.g., wortmannin [110], Ly294002, staurosporine, quercetin, demethoxyviridin and PI-103 among others. Wortmannin and demethoxyviridin are potent, irreversible, but nonselective inhibitors of all PI3K. LY-294002 and quercetin are reversible and potent PI3K inhibitors, but non-selective and also bind other members of the PI3K family [111]. Most protein kinase inhibitors block access of ATP to the ATPbinding pocket by distinct stoichiometric interactions [112]. Wortmannin has shown activity against tumor xenografts from melanoma [113], breast [114], colon [114], ovarian [114], and pancreatic cancer [115]. Treating EGFRvIII glioma cell lines with wortmannin significantly suppressed cell growth to a similar extent as EGFR inhibitors [116]. Wortmannin has also been shown to be an effective radiosensitizer of glioma cells [117], and displayed, when tested on a panel of GBM cell lines, a slight pro-apoptotic effect [106]. LY-294002 efficacy has been studied in glioma cell lines. It significantly reduced the level of PtdIns $(3,4,5) \mathrm{P}_{3}$, inactivated phospho-PKB, and blocked cell proliferation in a dose-dependent manner [118]. Moreover, Ly294002 blocks p53 induction by inhibiting stabilization of p53. Nevertheless, this down-regulatory effect on p53 by PI3K inhibitors (attenuating p53-dependent cell death) [119] may not be so relevant for many cancers, since the p53 pathway is inactivated in most cancers.

A new series of PI3K inhibitors, which selectively target different PI3K isoforms, were synthesized. The small molecule inhibitor PI-103 showed unique activity against genetically different GBM cell lines. PI-103 selectively blocked $\mathrm{p} 110 \alpha$ and mTOR complex at nanomolar concentration [120]. Only down-regulation of p110 $\alpha$ specifically blocked glioma proliferation in vitro, but not $\mathrm{p} 110 \beta$ [120]. PI-103 was efficient, irrespective of the genetic status of cell lines (PTEN, p53 and EGFR). In vivo data show that PI-103 was effective and non-toxic in glioma xenograft models $[120,121]$. Since mTOR inhibition may lead to PI3K activation, theoretically, blocking mTOR combined with a PI3K inhibitor may induce cell death. PI3K inhibitors like Ly294002 enhance apoptosis triggered by TRAIL or cytotoxics (vincristine, doxorubicine, etoposide, etc.) [122]. Recently, an interesting paper showed that HOXA9 transcription was activated in GBM leading to decreased apoptosis and increased proliferation. Transcriptional activation of HOXA cluster was blocked by PI3K inhibitor through an epigenetic mechanism involving histone H3k27 tri-methylation [123]. 


\section{PI3K downstream inhibition}

\section{PKB inhibition}

The serine/threonine kinase PKB is one of the enzymes regulated by $\mathrm{PI} 3 \mathrm{~K}$ activity by regulating PtdIns-3,4,5- $\mathrm{P}_{3}$ levels. Its activated form down-regulates Bad, caspase-9, GSK-3beta and forkhead transcription factors, suppressing apoptosis and promoting cell survival [31, 124]. In addition, PKB increased levels of vascular endothelial growth factor (VEGF) under hypoxic conditions [125]. PKB is activated in about $80 \%$ of GBM [126]. Activated PKB together with mutant Ras was found to be tumorigenic in a murine glioma model [68]. In another model using astrocytes expressing E6/E7, hTERT (human telomerase reverse transcriptase) and Ras, upgrading of a low-grade to a highgrade tumor was achieved by addition of activated PKB [127]. The effect of PKB in the regulation of cell cycle, apoptosis and angiogenesis of GBM cell lines strongly suggests a role in the development of GBM. The two PKB inhibitors, KP-372-1 and KP-37-2, induced apoptosis in GBM cells [128].

\section{mTOR inhibition}

The TOR family of proteins has multiple functions: regulation of mRNA transcription and translation in response to essential nutrients, membrane trafficking, protein degradation, organization of the actin cytoskeleton, and PKC signaling $[129,130]$. There is a rapamycin-sensitive mTORcomplex (mTORC1) and a rapamycin-insensitive complex (mTORC2). mTOR activates S6K1 and EBP1. mTOR can also be up-regulated indirectly through activation of PI3K and PKB. Different mTOR inhibitors have been developed and are being assessed in clinical trials: the rapamycin prototype and three rapamycin derivatives RAD001 (everolimus), CCI-779 (temsirolimus), and AP23573. All mTOR inhibitors form a complex with the intracellular immunophilin FKBP12 and inhibit mTOR. The wide spectrum of rapamycin covers infectious, immunosuppressive, endothelial and neurodegenerative disease.

Rapamycin has been shown to have a growth inhibitory effect in several human and murine cancer cell lines both in vitro and in a xenograft model [131-134]. Rapamycin induces a decrease in cyclin D1 expression and an increase in p27 levels, leading to a cell cycle block in late G1/Sphase [135]. Rapamycin has also been shown to induce cell death in a limited number of tumor models, although the molecular mechanism leading to apoptosis is not clear. One of the mechanisms may be that the downstream target of mTOR-S6K1-inactivates the pro-apoptotic molecule BAD [136, 137]. Recently, it has been shown that inhibition of mTOR/S6K1 triggers a negative feedback loop resulting in the activation of AKT signaling probably through a IGF-1R-dependent mechanism. Inhibiting mTOR also has an effect on the angiogenesis by blocking the translation of HIF- $\alpha$ [138]. Anti-angiogenic effects on endothelial cells have further been shown in a rapamycinsensitive murine tumor model [139]. An interesting paper from Liu et al. showed that NVP-BEZ235, a novel dual $\mathrm{PI} 3 \mathrm{~K} / \mathrm{mammalian}$ target of rapamycin (mTOR) inhibitor, was able to inhibit PI3K and mTOR signaling,and induce cell cycle arrest, down-regulation of VEGF and autophagy in gliomas [140]. Different studies combining mTOR inhibitors together with other anti-cancer compounds have been published with contradictory findings [106, 141, 142]; however, in vitro results may not predict clinical efficacy given the wide spectrum of rapamycin effects. Different clinical trials are now being performed for the rapamycin derivates CCI-779 (http://clinicaltrials.gov/ct2/results?term $=$ CCI-779), RAD001 (http://clinicaltrials.gov/ct2/results? term=RAD001) and AP23573 (http://clinicaltrials.gov/ct2/ results?term=AP23573) alone or in combination with other drugs. The most promising results have been described for renal cell carcinoma [143], endometrial cancer [144], and mantle cell lymphoma [145], but also giant cell astrocytoma in tuberous sclerosis patients. Phase II studies have been performed in recurrent GBM patients, with limited anti-tumor activity [146, 147]. Given the negative feedback loop between mTOR and PKB via IGF-1R, an mTOR inhibitor combined with an IGF-1R antibody/inhibitor may be a promising strategy to increase therapeutic efficacy [148].

\section{Drug combinations}

Use of drug combinations is of particular interest, given the limited responses obtained in clinical trials using single drug approaches. In cases of an additive or synergistic effect, drug doses of each respective compound can be reduced, potentially paralleled by a reduction in side effects. We studied the impact of different drug combinations on survival and proliferation of GBM cell lines. Targeting EGFR with AEE788 and PDGFR with Gleevec and/or mTOR with RAD001, we found that single and combined applications did not significantly enhance background apoptosis rates [106]. However, the combination of AEE788 with the microtubuli inhibitor patupilone induced apoptosis in some $50 \%$ of cell lines, which was accompanied by simultaneous inactivation of both p-ERK and p-PKB. Asking whether down-regulation of p-ERK and p-PKB is critical for GBM cell survival, we directly blocked the PI3K/PKB and Ras/Raf/MEK/ERK pathways with both the PI3K inhibitor wortmannin and the MEK inhibitor UO126. This combination frequently killed GBM cells, supporting a model of an additive effect by targeting 
these two signaling pathways that results in a reduced threshold for the induction of apoptosis. We did not find any correlation between the sensitivity or resistance of GBM cells to apoptosis and their genetic status [106]. Simultaneous treatment with rapamycin and the EGFR inhibitor (EKI-785) resulted in synergistic anti-proliferative and pro-apoptotic effects [149]. At a molecular level, rapamycin alone decreased S6 phosphorylation, while EGFR inhibitor reduced phosphorylation of STAT3 (signal transducer and activator of transcription). Rapamycin alone increased phosphorylation of PKB and promoted the binding of the translational inhibitor eukaryotic initiation factor 4 binding protein (4EBP1) to the eukaryotic translational initiation factor 4E (eIF4E), which are blocked by EGFR inhibition [150]. Simultaneous blocking of multiple enzyme activities may reduce the effect of compensatory signaling which is one of the therapeutic limitations of using single agent therapy. However, suppressing crosstalk may not be accompanied by an enhanced therapeutic effect. Furthermore, combining the anti-malaria drug artesunate (ART) with the EGFR inhibitor OSI-774 resulted in an in vitro cytostatic effect which was most pronounced in a background of constitutively active EGFR [151]. Results of a Phase II study of Imatinib mesylate (Gleevec) plus hydroxyurea showed that this combination was well tolerated and associated with a modest clinical response in a subgroup of patients with recurrent GBM [91]. PI3K inhibitor (as LY294002 and wormannin) sensitizes GBM cells to apoptosis. This mechanism act both activating extrinsic apoptosis through TRAIL (tumor necrosis factorrelated apoptosis-inducing ligand) and CD95 and the intrinsic mitochondrial apoptotic pathway [152].

\section{Conclusions}

The promise of Gleevec - the concept that each cancer may have its unique molecular signature that can be therapeutically exploited-has not yet been met. In GBM, there are a large number of different molecular targets, and the net effect on signaling by individual mutational patterns may also be unique for each tumor. Nonetheless, empirical drug combinations showed improved therapeutic effects over single agent approaches. A fundamental question is whether GBM have an Achilles heel or whether each tumor requires its individual drug combination. Components of the MAPK pathway, such as Raf [153] and MEK [106], displayed empirical evidence of efficacy when combined with drugs that target PKB/Akt [61] and mTOR [150]. Sublethal damage will select more malignant clones, considering the high degree of genetic instability of malignant human tumors [154]. Hence, therapeutic interference must aim at induction of tumor cell apoptosis. An interesting approach is to use drugs that exploit a general mechanism respecting individual patterns of alterations, e.g., epigenetic signatures of gene expression. For example, histone deacetylase inhibitory drugs induce re-expression of silenced genes in an unpredictable individual way, mimicking the stochastic nature of the disease [155]. Experimentally, HDAC inhibitory drugs displayed a remarkable pro-apoptotic effect upon combination with agents that block glucose utilization, such as 2-deoxy-glucose [156]. Combining new classes of cancer drugs with anti-metabolic strategies may lead to innovative new concepts to attack this disease, leading to enduring clinical responses by successful control of tumor cell proliferation, survival and invasion.

Open Access This article is distributed under the terms of the Creative Commons Attribution Noncommercial License which permits any noncommercial use, distribution, and reproduction in any medium, provided the original author(s) and source are credited.

\section{References}

1. Newton HB (1994) Primary brain tumors: review of etiology, diagnosis and treatment. Am Fam Physician 49(4):787-797

2. Davis FG, McCarthy BJ (2001) Current epidemiological trends and surveillance issues in brain tumors. Expert Rev Anticancer Ther 1(3):395-401

3. Newton HB (2004) Molecular neuro-oncology and development of targeted therapeutic strategies for brain tumors. Part 2: PI3K/ Akt/PTEN, mTOR, SHH/PTCH and angiogenesis. Expert Rev Anticancer Ther 4(1):105-128

4. Kleihues P, Sobin LH (2000) World Health Organization classification of tumors. Cancer 88(12):2887

5. Chung RY, Seizinger BR (1991) Tumor suppressor genes and cancer of the human nervous system. Cancer Invest 9(4): 429-437

6. Maher EA, Furnari FB, Bachoo RM et al (2001) Malignant glioma: genetics and biology of a grave matter. Genes Dev 15(11):1311-1333

7. von Deimling A, Louis DN, Wiestler OD (1995) Molecular pathways in the formation of gliomas. Glia 15(3):328-338

8. Knobbe CB, Merlo A, Reifenberger G (2002) Pten signaling in gliomas. Neuro-Oncology 4(3):196-211

9. Wong AJ, Ruppert JM, Bigner SH et al (1992) Structural alterations of the epidermal growth factor receptor gene in human gliomas. Proc Natl Acad Sci USA 89(7):2965-2969

10. Hurtt MR, Moossy J, Donovan-Peluso M, Locker J (1992) Amplification of epidermal growth factor receptor gene in gliomas: histopathology and prognosis. J Neuropathol Exp Neurol 51(1):84-90

11. Merlo A, Herman JG, Mao L et al (1995) $5^{\prime}$ CpG island methylation is associated with transcriptional silencing of the tumour suppressor p16/CDKN2/MTS1 in human cancers. Nat Med 1(7):686-692

12. Smith JS, Tachibana I, Passe SM et al (2001) PTEN mutation, EGFR amplification, and outcome in patients with anaplastic astrocytoma and glioblastoma multiforme. J Natl Cancer Inst 93(16): 1246-1256

13. Fueyo J, Gomez-Manzano C, Yung WK et al (1996) Adenovirus-mediated $\mathrm{p} 16 / \mathrm{CDKN} 2$ gene transfer induces growth arrest 
and modifies the transformed phenotype of glioma cells. Oncogene 12(1):103-110

14. Ohgaki H, Kleihues P (2005) Population-based studies on incidence, survival rates, and genetic alterations in astrocytic and oligodendroglial gliomas. J Neuropathol Exp Neurol 64(6): 479-489

15. Watanabe K, Sato K, Biernat W et al (1997) Incidence and timing of p53 mutations during astrocytoma progression in patients with multiple biopsies. Clin Cancer Res 3(4):523-530

16. Pomerantz J, Schreiber-Agus N, Liegeois NJ et al (1998) The Ink4a tumor suppressor gene product, p19Arf, interacts with MDM2 and neutralizes MDM2's inhibition of p53. Cell 92(6): $713-723$

17. Reifenberger J, Reifenberger G, Liu L, James CD, Wechsler W, Collins VP (1994) Molecular genetic analysis of oligodendroglial tumors shows preferential allelic deletions on $19 q$ and $1 p$. Am J Pathol 145(5):1175-1190

18. Hiraga S, Ohnishi T, Izumoto S et al (1998) Telomerase activity and alterations in telomere length in human brain tumors. Cancer Res 58(10):2117-2125

19. Parsons DW, Jones S, Zhang X et al (2008) An integrated genomic analysis of human glioblastoma multiforme. Science 321:1807-1812

20. Boulay JL, Miserez AR, Zweifel C et al (2007) Loss of NOTCH2 positively predicts survival in subgroups of human glial brain tumors. PLoS ONE 2(6):e576

21. Verhaak RG, Hoadley KA, Purdom E et al (2010) Integrated genomic analysis identifies clinically relevant subtypes of glioblastoma characterized by abnormalities in PDGFRA, IDH1, EGFR, and NF1. Cancer Cell 17(1):98-110

22. Wrensch M, Jenkins RB, Chang JS et al (2009) Variants in the CDKN2B and RTEL1 regions are associated with high-grade glioma susceptibility. Nat Genet 41(8):905-908

23. Hegi ME, Diserens AC, Gorlia T et al (2005) MGMT gene silencing and benefit from temozolomide in glioblastoma. N Engl J Med 352(10):997-1003

24. Hegi ME, Liu L, Herman JG et al (2008) Correlation of O6-methylguanine methyltransferase (MGMT) promoter methylation with clinical outcomes in glioblastoma and clinical strategies to modulate MGMT activity. J Clin Oncol 26(25): 4189-4199

25. Esteller M, Garcia-Foncillas J, Andion E et al (2000) Inactivation of the DNA-repair gene MGMT and the clinical response of gliomas to alkylating agents. N Engl J Med 343(19):1350-1354

26. (2008) Comprehensive genomic characterization defines human glioblastoma genes and core pathways. Nature 455(7216): 1061-1068

27. Kleihues P, Ohgaki H (1999) Primary and secondary glioblastomas: from concept to clinical diagnosis. Neuro-Oncology $1(1): 44-51$

28. Mellinghoff IK, Wang MY, Vivanco I et al (2005) Molecular determinants of the response of glioblastomas to EGFR kinase inhibitors. N Engl J Med 353(19):2012-2024

29. Kapoor GS, Christie A, O'Rourke DM (2007) EGFR inhibition in glioblastoma cells induces G2/M arrest and is independent of p53. Cancer Biol Ther 6(4):571-579

30. Liliental J, Moon SY, Lesche R et al (2000) Genetic deletion of the Pten tumor suppressor gene promotes cell motility by activation of Rac1 and Cdc42 GTPases. Curr Biol 10(7):401-404

31. Datta SR, Dudek H, Tao X et al (1997) Akt phosphorylation of BAD couples survival signals to the cell-intrinsic death machinery. Cell 91(2):231-241

32. Holland EC, Hively WP, DePinho RA, Varmus HE (1998) A constitutively active epidermal growth factor receptor cooperates with disruption of G1 cell-cycle arrest pathways to induce glioma-like lesions in mice. Genes Dev 12(23):3675-3685
33. Rossig L, Jadidi AS, Urbich C, Badorff C, Zeiher AM, Dimmeler S (2001) Akt-dependent phosphorylation of p21(Cip1) regulates PCNA binding and proliferation of endothelial cells. Mol Cell Biol 21(16):5644-5657

34. Schlessinger J (2000) Cell signaling by receptor tyrosine kinases. Cell 103(2):211-225

35. Shinojima N, Tada K, Shiraishi S et al (2003) Prognostic value of epidermal growth factor receptor in patients with glioblastoma multiforme. Cancer Res 63(20):6962-6970

36. Frederick L, Wang XY, Eley G, James CD (2000) Diversity and frequency of epidermal growth factor receptor mutations in human glioblastomas. Cancer Res 60(5):1383-1387

37. Heimberger AB, Suki D, Yang D, Shi W, Aldape K (2005) The natural history of EGFR and EGFRvIII in glioblastoma patients. J Transl Med 3:38

38. Fan QW, Cheng C, Knight ZA et al (2009) EGFR signals to mTOR through PKC and independently of Akt in glioma. Sci Signal 2(55):ra4

39. Vogt PK, Kang S (2006) Kinase inhibitors: vice becomes virtue. Cancer Cell 9(5):327-328

40. Vogt PK, Bader AG, Kang S (2006) PI 3-kinases: hidden potentials revealed. Cell Cycle 5(9):946-949

41. Katso R, Okkenhaug K, Ahmadi K, White S, Timms J, Waterfield MD (2001) Cellular function of phosphoinositide 3-kinases: implications for development, homeostasis, and cancer. Annu Rev Cell Dev Biol 17:615-675

42. Cantley LC (2002) The phosphoinositide 3-kinase pathway. Science 296(5573):1655-1657

43. Gymnopoulos M, Elsliger MA, Vogt PK (2007) Rare cancerspecific mutations in PIK3CA show gain of function. Proc Natl Acad Sci USA 104(13):5569-5574

44. Samuels Y, Wang Z, Bardelli A et al (2004) High frequency of mutations of the PIK3CA gene in human cancers. Science 304(5670):554

45. Gaidarov I, Smith ME, Domin J, Keen JH (2001) The class II phosphoinositide 3-kinase C2alpha is activated by clathrin and regulates clathrin-mediated membrane trafficking. Mol Cell 7(2):443-449

46. Byfield MP, Murray JT, Backer JM (2005) hVps34 is a nutrientregulated lipid kinase required for activation of p70 S6 kinase. J Biol Chem 280(38):33076-33082

47. Nobukuni T, Joaquin M, Roccio M et al (2005) Amino acids mediate $\mathrm{mTOR} /$ raptor signaling through activation of class 3 phosphatidylinositol 3OH-kinase. Proc Natl Acad Sci USA 102(40):14238-14243

48. Odorizzi G, Babst M, Emr SD (2000) Phosphoinositide signaling and the regulation of membrane trafficking in yeast. Trends Biochem Sci 25(5):229-235

49. Burgering BM, Medema RH (2003) Decisions on life and death: FOXO Forkhead transcription factors are in command when $\mathrm{PKB} /$ Akt is off duty. J Leukoc Biol 73(6):689-701

50. Vivanco I, Sawyers CL (2002) The phosphatidylinositol 3-kinase AKT pathway in human cancer. Nat Rev Cancer 2(7): 489-501

51. Van Haastert PJ, Devreotes PN (2004) Chemotaxis: signalling the way forward. Nat Rev Mol Cell Biol 5(8):626-634

52. Dugani CB, Klip A (2005) Glucose transporter 4: cycling, compartments and controversies. EMBO Rep 6(12):1137-1142

53. Murga C, Zohar M, Teramoto H, Gutkind JS (2002) Rac1 and RhoG promote cell survival by the activation of PI3K and Akt, independently of their ability to stimulate JNK and NF-kappaB. Oncogene 21(2):207-216

54. Nguyen KT, Zong CS, Uttamsingh S et al (2002) The role of phosphatidylinositol 3-kinase, rho family GTPases, and STAT3 in Ros-induced cell transformation. J Biol Chem 277(13): 11107-11115 
55. Disanza A, Steffen A, Hertzog M, Frittoli E, Rottner K, Scita G (2005) Actin polymerization machinery: the finish line of signaling networks, the starting point of cellular movement. Cell Mol Life Sci 62(9):955-970

56. Yamazaki D, Kurisu S, Takenawa T (2005) Regulation of cancer cell motility through actin reorganization. Cancer Sci 96(7): 379-386

57. Hartmann C, Bartels G, Gehlhaar C, Holtkamp N, von Deimling A (2005) PIK3CA mutations in glioblastoma multiforme. Acta Neuropathol 109(6):639-642

58. Campbell IG, Russell SE, Choong DY et al (2004) Mutation of the PIK3CA gene in ovarian and breast cancer. Cancer Res 64(21):7678-7681

59. Broderick DK, Di C, Parrett TJ et al (2004) Mutations of PIK3CA in anaplastic oligodendrogliomas, high-grade astrocytomas, and medulloblastomas. Cancer Res 64(15):50485050

60. Lee JW, Soung YH, Kim SY et al (2005) PIK3CA gene is frequently mutated in breast carcinomas and hepatocellular carcinomas. Oncogene 24(8):1477-1480

61. Wymann MP, Marone R (2005) Phosphoinositide 3-kinase in disease: timing, location, and scaffolding. Curr Opin Cell Biol 17(2):141-149

62. Foukas LC, Claret M, Pearce W et al (2006) Critical role for the p110alpha phosphoinositide-3-OH kinase in growth and metabolic regulation. Nature 441(7091):366-370

63. Gallia GL, Rand V, Siu IM et al (2006) PIK3CA gene mutations in pediatric and adult glioblastoma multiforme. Mol Cancer Res 4(10):709-714

64. Li J, Yen C, Liaw D et al (1997) PTEN, a putative protein tyrosine phosphatase gene mutated in human brain, breast, and prostate cancer. Science 275(5308):1943-1947

65. Maier D, Zhang Z, Taylor E et al (1998) Somatic deletion mapping on chromosome 10 and sequence analysis of PTEN/MMAC1 point to the 10q25-26 region as the primary target in low-grade and high-grade gliomas. Oncogene 16(25):3331-3335

66. Knobbe CB, Reifenberger J, Blaschke B, Reifenberger G (2004) Hypermethylation and transcriptional downregulation of the carboxyl-terminal modulator protein gene in glioblastomas. J Natl Cancer Inst 96(6):483-486

67. Knobbe CB, Trampe-Kieslich A, Reifenberger G (2005) Genetic alteration and expression of the phosphoinositol-3-kinase/Akt pathway genes PIK3CA and PIKE in human glioblastomas. Neuropathol Appl Neurobiol 31(5):486-490

68. Holland EC, Celestino J, Dai C, Schaefer L, Sawaya RE, Fuller GN (2000) Combined activation of Ras and Akt in neural progenitors induces glioblastoma formation in mice. Nat Genet 25(1):55-57

69. Di Cristofano A, Pesce B, Cordon-Cardo C, Pandolfi PP (1998) Pten is essential for embryonic development and tumour suppression. Nat Genet 19(4):348-355

70. Engelman JA, Luo J, Cantley LC (2006) The evolution of phosphatidylinositol 3-kinases as regulators of growth and metabolism. Nat Rev Genet 7(8):606-619

71. Baeza N, Weller M, Yonekawa Y, Kleihues P, Ohgaki H (2003) PTEN methylation and expression in glioblastomas. Acta Neuropathol 106(5):479-485

72. Xiao A, Yin C, Yang C, Di Cristofano A, Pandolfi PP, Van Dyke $\mathrm{T}$ (2005) Somatic induction of Pten loss in a preclinical astrocytoma model reveals major roles in disease progression and avenues for target discovery and validation. Cancer Res 65(12): $5172-5180$

73. Wei Q, Clarke L, Scheidenhelm DK et al (2006) High-grade glioma formation results from postnatal pten loss or mutant epidermal growth factor receptor expression in a transgenic mouse glioma model. Cancer Res 66(15):7429-7437
74. Adachi J, Ohbayashi K, Suzuki T, Sasaki T (1999) Cell cycle arrest and astrocytic differentiation resulting from PTEN expression in glioma cells. J Neurosurg 91(5):822-830

75. Groszer M, Erickson R, Scripture-Adams DD et al (2001) Negative regulation of neural stem/progenitor cell proliferation by the Pten tumor suppressor gene in vivo. Science 294(5549): 2186-2189

76. Groszer M, Erickson R, Scripture-Adams DD et al (2006) PTEN negatively regulates neural stem cell self-renewal by modulating G0-G1 cell cycle entry. Proc Natl Acad Sci USA 103(1): 111-116

77. Wick W, Furnari FB, Naumann U, Cavenee WK, Weller M (1999) PTEN gene transfer in human malignant glioma: sensitization to irradiation and CD95L-induced apoptosis. Oncogene 18(27):3936-3943

78. Ermoian RP, Furniss CS, Lamborn KR et al (2002) Dysregulation of PTEN and protein kinase B is associated with glioma histology and patient survival. Clin Cancer Res 8(5):1100-1106

79. Sasaki H, Zlatescu MC, Betensky RA, Ino Y, Cairncross JG, Louis DN (2001) PTEN is a target of chromosome 10q loss in anaplastic oligodendrogliomas and PTEN alterations are associated with poor prognosis. Am J Pathol 159(1):359-367

80. Ueki K, Yballe CM, Brachmann SM et al (2002) Increased insulin sensitivity in mice lacking p85beta subunit of phosphoinositide 3-kinase. Proc Natl Acad Sci USA 99(1):419-424

81. Terauchi Y, Tsuji Y, Satoh S et al (1999) Increased insulin sensitivity and hypoglycaemia in mice lacking the p85 alpha subunit of phosphoinositide 3-kinase. Nat Genet 21(2): 230-235

82. Mauvais-Jarvis F, Ueki K, Fruman DA et al (2002) Reduced expression of the murine p85alpha subunit of phosphoinositide 3-kinase improves insulin signaling and ameliorates diabetes. J Clin Invest 109(1):141-149

83. Bi L, Okabe I, Bernard DJ, Nussbaum RL (2002) Early embryonic lethality in mice deficient in the p110beta catalytic subunit of PI 3-kinase. Mamm Genome 13(3):169-172

84. Bi L, Okabe I, Bernard DJ, Wynshaw-Boris A, Nussbaum RL (1999) Proliferative defect and embryonic lethality in mice homozygous for a deletion in the p110alpha subunit of phosphoinositide 3-kinase. J Biol Chem 274(16):10963-10968

85. Jia S, Liu Z, Zhang S et al (2008) Essential roles of PI(3)Kp110beta in cell growth, metabolism and tumorigenesis. Nature 454(7205):776-779

86. Lefranc F, Brotchi J, Kiss R (2005) Possible future issues in the treatment of glioblastomas: special emphasis on cell migration and the resistance of migrating glioblastoma cells to apoptosis. J Clin Oncol 23(10):2411-2422

87. Stupp R, Mason WP, van den Bent MJ et al (2005) Radiotherapy plus concomitant and adjuvant temozolomide for glioblastoma. N Engl J Med 352(10):987-996

88. Kneifel S, Cordier D, Good S et al (2006) Local targeting of malignant gliomas by the diffusible peptidic vector $1,4,7,10$ tetraazacyclododecane-1-glutaric acid-4,7,10-triacetic acid-substance p. Clin Cancer Res 12(12):3843-3850

89. Merlo A, Hausmann O, Wasner M et al (1999) Locoregional regulatory peptide receptor targeting with the diffusible somatostatin analogue 90Y-labeled DOTA0-D-Phe1-Tyr3octreotide (DOTATOC): a pilot study in human gliomas. Clin Cancer Res 5(5):1025-1033

90. Raizer JJ, Malkin MG, Kleber M, Abrey LE (2004) Phase 1 study of 28-day, low-dose temozolomide and BCNU in the treatment of malignant gliomas after radiation therapy. NeuroOncology 6(3):247-252

91. Reardon DA, Egorin MJ, Quinn JA et al (2005) Phase II study of imatinib mesylate plus hydroxyurea in adults with recurrent glioblastoma multiforme. J Clin Oncol 23(36):9359-9368 
92. Pfeffer MR, Levitt ML, Aderka D (2004) Gefitinib in recurrent glioblastoma. J Clin Oncol 22(13):2755-2756; author reply 2756

93. Groves MD, Puduvalli VK, Hess KR et al (2002) Phase II trial of temozolomide plus the matrix metalloproteinase inhibitor, marimastat, in recurrent and progressive glioblastoma multiforme. J Clin Oncol 20(5):1383-1388

94. Baka S, Clamp AR, Jayson GC (2006) A review of the latest clinical compounds to inhibit VEGF in pathological angiogenesis. Expert Opin Ther Targets 10(6):867-876

95. Puduvalli VK (2004) Inhibition of angiogenesis as a therapeutic strategy against brain tumors. Cancer Treat Res 117:307-336

96. Lamszus K, Heese O, Westphal M (2004) Angiogenesis-related growth factors in brain tumors. Cancer Treat Res 117:169-190

97. Morabito A, Fanelli M, Carillio G, Gattuso D, Sarmiento R, Gasparini G (2004) Thalidomide prolongs disease stabilization after conventional therapy in patients with recurrent glioblastoma. Oncol Rep 11(1):93-95

98. Collins I, Workman P (2006) New approaches to molecular cancer therapeutics. Nat Chem Biol 2(12):689-700

99. Luwor RB, Johns TG, Murone C et al (2001) Monoclonal antibody 806 inhibits the growth of tumor xenografts expressing either the de2-7 or amplified epidermal growth factor receptor (EGFR) but not wild-type EGFR. Cancer Res 61(14):5355-5361

100. Marshall J (2006) Clinical implications of the mechanism of epidermal growth factor receptor inhibitors. Cancer 107(6): $1207-1218$

101. Eller JL, Longo SL, Hicklin DJ, Canute GW (2002) Activity of anti-epidermal growth factor receptor monoclonal antibody C225 against glioblastoma multiforme. Neurosurgery 51(4): 1005-1013; discussion 1013-1004

102. Baselga J (2001) The EGFR as a target for anticancer therapyfocus on cetuximab. Eur J Cancer 37(Suppl 4):S16-S22

103. Rich JN, Reardon DA, Peery T et al (2004) Phase II trial of gefitinib in recurrent glioblastoma. J Clin Oncol 22(1):133-142

104. Daneshmand M, Parolin DA, Hirte HW et al (2003) A pharmacodynamic study of the epidermal growth factor receptor tyrosine kinase inhibitor ZD1839 in metastatic colorectal cancer patients. Clin Cancer Res 9(7):2457-2464

105. Thatcher N, Chang A, Parikh P et al (2005) Gefitinib plus best supportive care in previously treated patients with refractory advanced non-small-cell lung cancer: results from a randomised, placebo-controlled, multicentre study (Iressa Survival Evaluation in Lung Cancer). Lancet 366(9496):1527-1537

106. Failly M, Korur S, Egler V et al (2007) Combination of sublethal concentrations of epidermal growth factor receptor inhibitor and microtubule stabilizer induces apoptosis of glioblastoma cells. Mol Cancer Ther 6(2):773-781

107. Fan QW, Cheng CK, Nicolaides TP et al (2007) A dual phosphoinositide-3-kinase alpha/mTOR inhibitor cooperates with blockade of epidermal growth factor receptor in PTEN-mutant glioma. Cancer Res 67(17):7960-7965

108. Mukherjee B, McEllin B, Camacho CV et al (2009) EGFRvIII and DNA double-strand break repair: a molecular mechanism for radioresistance in glioblastoma. Cancer Res 69(10):4252-4259

109. Cemeus C, Zhao TT, Barrett GM, Lorimer IA, Dimitroulakos J (2008) Lovastatin enhances gefitinib activity in glioblastoma cells irrespective of EGFRvIII and PTEN status. J Neurooncol 90(1):9-17

110. Arcaro A, Wymann MP (1993) Wortmannin is a potent phosphatidylinositol 3-kinase inhibitor: the role of phosphatidylinositol 3,4,5-trisphosphate in neutrophil responses. Biochem $\mathbf{J}$ 296(Pt 2):297-301

111. Walker EH, Pacold ME, Perisic O et al (2000) Structural determinants of phosphoinositide 3-kinase inhibition by wortmannin, LY294002, quercetin, myricetin, and staurosporine. Mol Cell 6(4):909-919

112. Toledo LM, Lydon NB, Elbaum D (1999) The structure-based design of ATP-site directed protein kinase inhibitors. Curr Med Chem 6(9):775-805

113. Meier F, Busch S, Lasithiotakis K et al (2007) Combined targeting of MAPK and AKT signalling pathways is a promising strategy for melanoma treatment. $\mathrm{Br} \mathrm{J}$ Dermatol 156(6): 1204-1213

114. Schultz RM, Merriman RL, Andis SL et al (1995) In vitro and in vivo antitumor activity of the phosphatidylinositol-3-kinase inhibitor, wortmannin. Anticancer Res 15(4):1135-1139

115. Bondar VM, Sweeney-Gotsch B, Andreeff M, Mills GB, McConkey DJ (2002) Inhibition of the phosphatidylinositol $3^{\prime}$-kinase-AKT pathway induces apoptosis in pancreatic carcinoma cells in vitro and in vivo. Mol Cancer Ther 1(12):989997

116. Klingler-Hoffmann M, Bukczynska P, Tiganis T (2003) Inhibition of phosphatidylinositol 3-kinase signaling negates the growth advantage imparted by a mutant epidermal growth factor receptor on human glioblastoma cells. Int J Cancer 105(3): 331-339

117. Kubota N, Okada S, Inada T, Ohnishi K, Ohnishi T (2000) Wortmannin sensitizes human glioblastoma cell lines carrying mutant and wild type TP53 gene to radiation. Cancer Lett 161(2):141-147

118. Shingu T, Yamada K, Hara N et al (2003) Growth inhibition of human malignant glioma cells induced by the PI3-K-specific inhibitor. J Neurosurg 98(1):154-161

119. Bar J, Lukaschuk N, Zalcenstein A, Wilder S, Seger R, Oren M (2005) The PI3K inhibitor LY294002 prevents p53 induction by DNA damage and attenuates chemotherapy-induced apoptosis. Cell Death Differ 12:1578-1587

120. Fan QW, Knight ZA, Goldenberg DD et al (2006) A dual PI3 kinase/mTOR inhibitor reveals emergent efficacy in glioma. Cancer Cell 9(5):341-349

121. Fan QW, Weiss WA (2006) Isoform specific inhibitors of PI3 kinase in glioma. Cell Cycle 5(20):2301-2305

122. Opel D, Westhoff MA, Bender A, Braun V, Debatin KM, Fulda S (2008) Phosphatidylinositol 3-kinase inhibition broadly sensitizes glioblastoma cells to death receptor- and drug-induced apoptosis. Cancer Res 68(15):6271-6280

123. Costa BM, Smith JS, Chen Y et al (2010) Reversing HOXA9 oncogene activation by PI3K inhibition: epigenetic mechanism and prognostic significance in human glioblastoma. Cancer Res 70(2):453-462

124. del Peso L, Gonzalez-Garcia M, Page C, Herrera R, Nunez G (1997) Interleukin-3-induced phosphorylation of BAD through the protein kinase Akt. Science 278(5338):687-689

125. Mazure NM, Chen EY, Laderoute KR, Giaccia AJ (1997) Induction of vascular endothelial growth factor by hypoxia is modulated by a phosphatidylinositol 3-kinase/Akt signaling pathway in Ha-ras-transformed cells through a hypoxia inducible factor-1 transcriptional element. Blood 90(9): 3322-3331

126. Haas-Kogan D, Shalev N, Wong M, Mills G, Yount G, Stokoe D (1998) Protein kinase B (PKB/Akt) activity is elevated in glioblastoma cells due to mutation of the tumor suppressor PTEN/ MMAC. Curr Biol 8(21):1195-1198

127. Sonoda Y, Ozawa T, Hirose Y et al (2001) Formation of intracranial tumors by genetically modified human astrocytes defines four pathways critical in the development of human anaplastic astrocytoma. Cancer Res 61(13):4956-4960

128. Koul D, Shen R, Bergh S et al (2006) Inhibition of Akt survival pathway by a small-molecule inhibitor in human glioblastoma. Mol Cancer Ther 5(3):637-644 
129. Hay N, Sonenberg N (2004) Upstream and downstream of mTOR. Genes Dev 18(16):1926-1945

130. Schmelzle T, Hall MN (2000) TOR, a central controller of cell growth. Cell 103(2):253-262

131. Busca R, Bertolotto C, Ortonne JP, Ballotti R (1996) Inhibition of the phosphatidylinositol 3-kinase/p70(S6)-kinase pathway induces B16 melanoma cell differentiation. J Biol Chem 271(50): 31824-31830

132. Grewe M, Gansauge F, Schmid RM, Adler G, Seufferlein T (1999) Regulation of cell growth and cyclin D1 expression by the constitutively active FRAP-p70s6K pathway in human pancreatic cancer cells. Cancer Res 59(15):3581-3587

133. Huang S, Houghton PJ (2001) Mechanisms of resistance to rapamycins. Drug Resist Updat 4(6):378-391

134. Houghton PJ, Huang S (2004) mTOR as a target for cancer therapy. Curr Top Microbiol Immunol 279:339-359

135. Hashemolhosseini S, Nagamine Y, Morley SJ, Desrivieres S, Mercep L, Ferrari S (1998) Rapamycin inhibition of the G1 to S transition is mediated by effects on cyclin D1 mRNA and protein stability. J Biol Chem 273(23):14424-14429

136. Castedo M, Roumier T, Blanco J et al (2002) Sequential involvement of Cdk1, mTOR and p53 in apoptosis induced by the HIV-1 envelope. EMBO J 21(15):4070-4080

137. Decaudin D, Geley S, Hirsch T et al (1997) Bcl-2 and Bcl-XL antagonize the mitochondrial dysfunction preceding nuclear apoptosis induced by chemotherapeutic agents. Cancer Res 57(1):62-67

138. Balcarcel RR, Stephanopoulos G (2001) Rapamycin reduces hybridoma cell death and enhances monoclonal antibody production. Biotechnol Bioeng 76(1):1-10

139. Guba M, von Breitenbuch P, Steinbauer M et al (2002) Rapamycin inhibits primary and metastatic tumor growth by antiangiogenesis: involvement of vascular endothelial growth factor. Nat Med 8(2):128-135

140. Liu TJ, Koul D, LaFortune T et al (2009) NVP-BEZ235, a novel dual phosphatidylinositol 3-kinase/mammalian target of rapamycin inhibitor, elicits multifaceted antitumor activities in human gliomas. Mol Cancer Ther 8(8):2204-2210

141. Weppler SA, Krause M, Zyromska A, Lambin P, Baumann M, Wouters BG (2007) Response of U87 glioma xenografts treated with concurrent rapamycin and fractionated radiotherapy: possible role for thrombosis. Radiother Oncol 82(1):96-104

142. Panner A, Parsa AT, Pieper RO (2006) Use of APO2L/TRAIL with mTOR inhibitors in the treatment of glioblastoma multiforme. Expert Rev Anticancer Ther 6(9):1313-1322

143. Ferretti G (2007) Temsirolimus for advanced renal-cell carcinoma. N Engl J Med 357(10):1050; author reply 1050-1051
144. Zhou C, Gehrig PA, Whang YE, Boggess JF (2003) Rapamycin inhibits telomerase activity by decreasing the hTERT mRNA level in endometrial cancer cells. Mol Cancer Ther 2(8): 789-795

145. Witzig TE, Geyer SM, Ghobrial I et al (2005) Phase II trial of single-agent temsirolimus (CCI-779) for relapsed mantle cell lymphoma. J Clin Oncol 23(23):5347-5356

146. Galanis E, Buckner JC, Maurer MJ et al (2005) Phase II trial of temsirolimus (CCI-779) in recurrent glioblastoma multiforme: a North Central Cancer Treatment Group Study. J Clin Oncol 23(23):5294-5304

147. Chang SM, Wen P, Cloughesy T et al (2005) Phase II study of CCI-779 in patients with recurrent glioblastoma multiforme. Investig New Drugs 23(4):357-361

148. Beier D, Hau P, Proescholdt M et al (2007) CD133(+) and CD133(-) glioblastoma-derived cancer stem cells show differential growth characteristics and molecular profiles. Cancer Res 67(9):4010-4015

149. Li B, Chang CM, Yuan M, McKenna WG, Shu HK (2003) Resistance to small molecule inhibitors of epidermal growth factor receptor in malignant gliomas. Cancer Res 63(21): 7443-7450

150. Rao RD, Mladek AC, Lamont JD et al (2005) Disruption of parallel and converging signaling pathways contributes to the synergistic antitumor effects of simultaneous mTOR and EGFR inhibition in GBM cells. Neoplasia 7(10):921-929

151. Efferth T, Ramirez T, Gebhart E, Halatsch ME (2004) Combination treatment of glioblastoma multiforme cell lines with the anti-malarial artesunate and the epidermal growth factor receptor tyrosine kinase inhibitor OSI-774. Biochem Pharmacol 67(9):1689-1700

152. Taylor RC, Cullen SP, Martin SJ (2008) Apoptosis: controlled demolition at the cellular level. Nat Rev Mol Cell Biol 9(3): 231-241

153. Lyustikman Y, Momota H, Pao W, Holland EC (2008) Constitutive activation of Raf-1 induces glioma formation in mice. Neoplasia 10(5):501-510

154. Bielas JH, Loeb KR, Rubin BP, True LD, Loeb LA (2006) Human cancers express a mutator phenotype. Proc Natl Acad Sci USA 103(48):18238-18242

155. Rosato RR, Grant S (2003) Histone deacetylase inhibitors in cancer therapy. Cancer Biol Ther 2(1):30-37

156. Egler V, Korur S, Failly M et al (2008) Histone deacetylase inhibition and blockade of the glycolytic pathway synergistically induce glioblastoma cell death. Clin Cancer Res 14(10): 3132-3140 